\title{
Ability of Muscidifurax raptorellus and Other Parasitoids and Predators to Control Drosophila suzukii Populations in Raspberries in the Laboratory
}

\author{
Phanie Bonneau ${ }^{1,2, *}$, Justin Renkema ${ }^{3}$, Valérie Fournier ${ }^{1}$ and Annabelle Firlej ${ }^{2}$ \\ 1 Centre de Recherche en Innovation sur les Végétaux (CRIV), Université Laval, Québec City, QC G1V 0A6, \\ Canada; valerie.fournier@fsaa.ulaval.ca \\ 2 Institut de Recherche et de Développement en Agroenvironnement (IRDA), Saint-Bruno-de-Montarville, \\ QC J3V 0G7, Canada; annabelle.firlej@irda.qc.ca \\ 3 London Research and Development Centre-Vineland Campus, Agriculture and Agri-Food Canada, \\ Vineland Station, ON LOR 2E0, Canada; justin.renkema@canada.ca \\ * Correspondence: phanie.bonneau.1@ulaval.ca
}

Received: 12 January 2019; Accepted: 27 February 2019; Published: 7 March 2019

\begin{abstract}
Drosophila suzukii is an invasive pest and economic threat to berry crops in Europe and the Americas. Current methods of control of this pest rely primarily on frequent applications of insecticides; therefore, there is a need for alternative control methods to reduce insecticide reliance. In this study, we evaluated the biological control potential of three parasitoid wasps: Diglyphus isaea, Muscidifurax raptorellus and Pachycrepoideus vindemmiae, and four predators: Chrysoperla carnea, Dicyphus hesperus, Orius insidiosus and Podisus maculiventris. Experiments were conducted for 15 days under controlled conditions in experimental arenas with $D$. suzukii females and raspberries, allowing for all life stages of $D$. suzukii to be available to natural enemies. Results showed the first evidence of $M$. raptorellus's ability to parasitize D. suzukii, resulting in a $40 \%$ reduction. Orius insidiosus, P. vindemmiae and C. carnea were also efficient, reducing D. suzukii numbers by $49 \%, 43 \%$ and $32 \%$, respectively. Predator preferences for each $D$. suzukii life stage were assessed. The clutch size, sex ratio and adult size variability of $D$. suzukii pupal parasitoids were also evaluated. This study expands the list of species that can effectively parasitize D. suzukii and provides new insights into the biological responses of M. raptorellus to D. suzukii pupae.
\end{abstract}

Keywords: Drosophila suzukii; biological control; invasive pest; host-parasitoid interactions; predation

\section{Introduction}

Drosophila suzukii Matsumura (Diptera: Drosophilidae) is an invasive pest from Asia that is now considered a major economic threat to soft fruit crops in Europe and the Americas, causing up to $80 \%$ yield loss in some crops [1]. Unlike other vinegar flies which prefer decaying fruit, D. suzukii females damage ripening fruits by laying their eggs with a serrated ovipositor and most damage is caused by larvae feeding on the fruit pulp [2]. Raspberry, strawberry, blackberry, blueberry and cherry have been the main crops affected by D. suzukii since its invasion in 2008 in North America [1,3,4]. Raspberries are D. suzukii's preferred host, with approximately $\$ 40$ million in losses from 2009 to 2014 in California [5].

Synthetic insecticides are the primary control method for $D$. suzukii but repeated interventions may promote insect resistance and most products target only the adult stage, which is outside the fruit $[6,7]$. Spinosad (Entrust SC) is an effective biological insecticide for organic growers, but preharvest intervals and the number of allowable applications per season per crop make management difficult [8]. There are 
a few alternatives to chemical control: cultural control (sanitation, exclusion nets, mass trapping) and biological control [4,9-11].

Biological control may be an ecological, efficient and cost-effective strategy for organic growers, targeting D. suzukii life stages that are inaccessible by insecticides, without generating development of resistance. Indigenous natural enemies are likely present and may play a role in reducing $D$. suzukii in both cropped and uncultivated habitats, hence the crucial importance of conservation of natural enemies' biodiversity [11-13]. Reducing the use of synthetic chemical insecticides and promoting integrated pest management (IPM) approaches may contribute to the preservation of natural enemies' richness and activity [14]. However, these beneficial insects might not be present in adequate numbers to provide effective control of $D$. suzukii in high value fruit crops with a low economic injury level $[5,11]$. Artificially multiplying effective beneficial insects and releasing them en masse would increase their numbers and activity in fruit crop ecosystems but require farmers to use environmentally safe and compatible external inputs [15]. Predators and parasitoids are commonly used as biological control agents and, while parasitoids are mostly specific and have a high self-propagating capacity, predators are more generalist and have the ability to actively capture and suppress their prey without delay [15]. Therefore, augmentative releases of predators and parasitoids may be a relevant strategy to reduce D. suzukii populations, not only in fruit crops, but also in closely adjacent vegetation [16]. Consequently, methods for the augmentative releases of natural enemies against $D$. suzukii need more research before recommendations can be made.

Research on classical biological control of D. suzukii has shown that larval endoparasitoids Asobara japonica Belokobylskij (Hymenoptera: Braconidae), Ganaspis brasiliensis Ihering and Leptopilina japonica japonica Novkovic and Kimura (Hymenoptera: Figitidae) from D. suzukii's native range can develop successfully from $D$. suzukii [17]. However, satisfying regulations to avoid non-target effects on native species and the ecosystem make the importation of exotic biological control agents an onerous and lengthy procedure [18]. Meanwhile, native natural enemies such as parasitoids and predators that are already in the invaded area of $D$. suzukii may be able to adapt and would provide a prompter solution than classical biological control agents.

In North America and Europe, studies on native pupal ectoparasitoids demonstrated that Pachycrepoideus vindemmiae Rondani (Hymenoptera: Pteromalidae) and Trichopria drosophilae Perkins (Hymenoptera: Diapriidae) parasitized 53\%-60\% and 38\%-76\%, respectively, of D. suzukii in the laboratory $[19,20]$. However, there are few studies of other parasitoids native to North America that may be able to use D. suzukii pupae as hosts [21], and the majority of parasitoids tested against D. suzukii are not currently commercially available. Therefore, it is crucial to find other successful native parasitoids readily available to berry growers in North America.

In parallel, North American and European studies on Orius spp. (Heteroptera: Anthocoridae), Anthocoris nemoralis Fabricius (Heteroptera: Anthocoridae), Dalotia coriaria Kraatz (Coleoptera: Staphylinidae) and Labidura riparia Pallas (Dermaptera: Labiduridae) confirmed that these predators can feed on D. suzukii larval, pupal or adult life stages [22-25]. However, predator efficacy for D. suzukii control has been highly variable in these studies, and few have investigated egg predation [26,27].

In order to reduce insecticide reliance, the primary goal of this study was to evaluate commercially-available natural enemies not previously tested against $D$. suzukii and to test their effectiveness with a life-stage specific experiment (for some predators) and when simultaneously presented with multiple $D$. suzukii life stages in infested raspberries. Therefore, a suite of available natural enemies for eventual augmentative releases including two parasitoid wasps and four insect predators was chosen from distributors in Canada.

The selected parasitoid wasps were a pupal ectoparasitoid, Muscidifurax raptorellus Kogan and Legner (Hymenoptera: Pteromalidae) and a larval ectoparasitoid Diglyphus isaea Walker (Hymenoptera: Eulophidae). The gregarious idiobiont $M$. raptorellus, a filth fly parasite commonly used in augmentative biological control in livestock operations, was chosen because of its wide range of potential dipteran hosts under a large scope of production systems and in many different geographic 
areas $[28,29]$. Gregarious D. isaea parasitizes a wide variety of dipteran leafminers and was selected for its ability to inspect the plant to find hidden fly larvae [30]. For comparison purposes, the solitary $P$. vindemmiae was included and the parasitoid clutch size, sex ratio and size variability of successfully emerged adults were recorded.

The selected generalist predators were Podisus maculiventris Say (Hemiptera: Pentatomidae), Dicyphus hesperus Knight (Heteroptera: Miridae) and larval Chrysoperla carnea Stephens (Neuroptera: Chrysopidae). The predatory shield bug P. maculiventris was chosen because it attacks the eggs, larvae and adults of more than 90 arthropod species spread over eight orders [31]. The polyphagous predatory mirid $D$. hesperus occurs in a wide range of greenhouse crops, locates prey easily [32] and was selected because a related species, Dicyphus tamaninii, has been found in D. suzukii-infested fruit [33]. Larval C. carnea, which is highly voracious, can consume 50 prey per day [34] and was selected for its wide host range, hunting capacity and resistance to certain pesticides [35]. None of these species have been evaluated against D. suzukii [26,27]. For comparison purposes, Orius insidiosus Say (Heteroptera: Anthocoridae) was included because it successfully caused $12-50 \%$ larval D. suzukii mortality in the laboratory [25].

\section{Materials and Methods}

\subsection{Insect Sources}

Drosophila suzukii was obtained from a colony maintained at $23 \pm 1{ }^{\circ} \mathrm{C} ; 16 \mathrm{~L}: 8 \mathrm{D} ; 50 \pm 10 \% \mathrm{RH}$ in plexiglass cages in the Institut de recherche et de développement en agroenvironnement (IRDA) in Saint-Bruno-de-Montarville, Quebec. The colony was started in summer 2014 from infested blueberry collected near St-Jude, Quebec. Eggs were laid in raspberries placed directly on the diet, in which larvae migrated. The diet consisted of a mixture of $70 \mathrm{~g}$ of brewer's yeast, $150 \mathrm{~g}$ of carrot powder, $2.5 \mathrm{~g}$ of sodium benzoate, $2 \mathrm{~g}$ of methylparaben, $50 \mathrm{~mL}$ of $1 \mathrm{~N} \mathrm{HCl}$ and $800 \mathrm{~mL}$ of distilled water. Flies were also provided with a mixture of white sugar and baker's yeast (1:1) in a Petri dish and water on a dental cotton roll.

The parasitoid wasp M. raptorellus was purchased from Bugs for Bugs (Guelph, ON, Canada). The parasitoid was sold as a mix in pupae of Musca domestica Linnaeus (Diptera: Muscidae), from which three parasitoid wasp species (Pteromalidae) emerge. Emerged parasitoids were sorted and male and female $M$. raptorellus were transferred using an insect vacuum to a separate plexiglass cage. Prior to use, parasitoids were provided with honey and water (1:1) on a dental cotton roll.

The parasitoid wasp $P$. vindemmiae was from a colony started in summer 2017 and maintained at $22 \pm 1{ }^{\circ} \mathrm{C} ; 16 \mathrm{~L}: 8 \mathrm{D} ; 55 \pm 10 \% \mathrm{RH}$ in a plexiglass cage in IRDA's laboratory. The colony was reared on D. suzukii pupae and originated from a P. vindemmiae colony at Agriculture and Agri-Food Canada (AAFC) in Agassiz, British Columbia, which was started from infested cherries collected near Summerland, British Columbia (BC), in 2015.

The larval predator $C$. carnea, the adult predator $O$. insidiosus and the parasitoid wasp D. isaea were purchased from PlantProducts (Leamington, ON, Canada) and kept in their shipping package with an ice pack for one day prior to use.

The adult predator $D$. hesperus and the nymph predator $P$. maculiventris were purchased from Anatis Bioprotection (Saint-Jacques-le-Mineur, QC, Canada) and kept in their shipping package with an ice pack for one day prior to use.

\subsection{Parasitoid and Predator Experiment with Multiple D. suzukii Life Stages}

The experimental arena was a clear plastic box (1 L) with a 40-cm length mesh sleeve with an opening on one end. Each arena contained five store-purchased red raspberries, washed in water, and placed in a clear plastic dish $(177 \mathrm{~mL}, 10-\mathrm{cm}$ diameter) with a cotton square to absorb excess liquid during the experiment. 
On day 1 of the experiments, five 3-day old D. suzukii mated adult females were placed in each plastic box to lay eggs in raspberries $\left(22 \pm 1{ }^{\circ} \mathrm{C} ; 16 \mathrm{~L}: 8 \mathrm{D} ; 55 \pm 10 \% \mathrm{RH}\right)$. Two raspberries were added to each plastic box every three days throughout the experiment in order to avoid the presence of decaying egg laying sites.

Eighteen females of each parasitoid species ( 3 to 5 days old and previously mated) or 18 individuals of each predator species were placed in arenas (one species per arena) on day 4 for larval parasitoids, on day 9 for pupal parasitoids and on day 3 for predators of the experiment, to ensure larvae and/or pupae were available. Eighteen parasitoids or predators were used based on the results of a pre-test with 12, 18 or 24 individuals and the densities used in a related study [36].

The experiments were conducted in two blocks, with the three parasitoid species and a control in the first and the four predator species and a control in the second. Each parasitoid and predator species was replicated eight times. After 15 days (time required to complete one $D$. suzukii life cycle under optimal laboratory conditions), the live predators, live parasitoids, D. suzukii larvae, pupae and live and dead adults were counted. The clear plastic dish with raspberries was filled with water so that D. suzukii larvae and pupae floated and could easily be removed and counted. The design of this experiment allowed age structure to be established so natural enemies were in the presence of all life stages of D. suzukii (egg, larva, pupa, adult) in each arena at the same time and the control (no natural enemies) was used as the base for comparisons among treatments.

For arenas with larval parasitoids, recovered $D$. suzukii larvae were placed in a 500-mL plastic container with a lid containing fine mesh for ventilation, filled with drosophila diet and kept in growth chambers for 35 days to determine the D. suzukii pupation rate or emergence rate of adult parasitoids. For arenas with pupal parasitoids, D. suzukii pupae recovered were placed singly in wells of an ELISA plate and kept in growth chambers for 35 days to determine the emergence rates of adult parasitoids or D. suzukii.

The success rate of parasitism (parasitoid adult emergence), the clutch size (number of parasitoids from one pupa), sex ratio and adult size variability were determined. The last three parameters are used in biological control studies to predict the efficacy of insect parasitoids and their foraging behavior [37]. While the clutch size and sex ratio are foraging decisions based on host quality, the progeny body size, directly influenced by the clutch size, is a direct indicator of fitness [37].

The adult parasitoid size was estimated by measuring the length $(\mathrm{mm})$ of the left hind tibia [38]. For $M$. raptorellus, the measurements of 15 males and 15 females that emerged from $M$. domestica pupae served as a control. For individuals from D. suzukii pupae recovered in the 15-day experiment, 15 males and 15 females were measured when there was one parasitoid per pupa and 15 pupae were randomly selected when there were two or more parasitoids per pupa. For P. vindemmiae, the measurements of 15 males and 15 females that emerged from D. suzukii pupae in the colony served as a control. For individuals from $D$. suzukii pupae recovered in the experiment, 15 males and 15 females were measured, as $P$. vindemmiae is a solitary pupal parasitoid. The measurements were made by removing the hind tibia from the body of the insect, photographing and measuring it with an electronic stereomicroscope, Zeiss SteREO Discovery V12 with Zeiss Axiocam 5033 Mpix video camera, using software, ZEN 2012 SP2 blue edition (@ Carl Zeiss Microscopy GmbH, 2011).

\subsection{Predator Experiment with Single D. suzukii Life Stage}

The experimental arena was a clear, plastic container with a lid $(177 \mathrm{~mL}, 10-\mathrm{cm}$ diameter $)$ and a raspberry leaf (cv. 'Polana') from unsprayed research plots that was laid flat and had its petiole inserted into a water-filled 2-mL microcentrifuge tube. Each arena contained six individuals of one D. suzukii life stage (eggs, larvae, pupae or adults) which were placed on top of the leaf which served as a support. Eggs were collected from a Petri dish filled with store-purchased raspberry jam that was placed in a D. suzukii colony cage for two hours. Eggs were rinsed with distilled water then placed on the central vein of the leaf with a paintbrush. Larvae and pupae were collected from the artificial diet used in the colony cage, rinsed with distilled water and placed onto leaves with a paintbrush. 
Adults were collected from the emerged pupae that were isolated in a cage to ensure that the flies were all five days old and three males and three females were placed into the experimental arenas using an insect vacuum. A predator (either adult $O$. insidiosus, adult $D$. hesperus, nymph $P$. maculiventris or larval C. carnea), starved for $24 \mathrm{~h}$, was placed in each arena. Arenas were held at $22 \pm 1{ }^{\circ} \mathrm{C} ; 16 \mathrm{~L}$ : $8 \mathrm{D}$; $55 \pm 10 \%$ RH in a growth chamber. No food was provided to $D$. suzukii adults or larvae to prevent predators from feeding on it. After $24 \mathrm{~h}$, predators were removed and the number of live $D$. suzukii individuals for each life stage was recovered from the leaves except for the pupae which were held seven additional days for adult emergence. There were 15 replications of each predator species and a control without a predator, for each of the four D. suzukii life stages.

\subsection{Data Analysis}

Data were tested with the Shapiro-Wilk test for normality and error variance for homoscedasticity, and analyses were conducted using JMP software (version 12.0.1, SAS Institute Inc., Cary, NC, USA). Data from the parasitoid and predator experiments with multiple D. suzukii life stages were analyzed using a one-way analysis of variance (ANOVA), followed by Tukey-Kramer's HSD $(p<0.05)$ for post-hoc comparisons effects of natural enemy species on the multiple $D$. suzukii life stages, except for D. suzukii live adult data, which were non-parametric and analyzed using a Kruskal-Wallis test, followed by post-hoc Dunn's test $(p<0.05)$. Data from the predator experiments with a single D. suzukii life stage were non-parametric and analyzed using a Kruskal-Wallis test, followed by post-hoc Dunn's test $(p<0.05)$ to compare means of live D. suzukii among predators. Data from parasitized D. suzukii pupae for each pupal parasitoid wasp species were analyzed using a Student's $t$-test $(p<0.05)$ to compare the parasitism rates. Data from individual parasitoid wasps that emerged from $D$. suzukii pupae were analyzed using a Chi-square test $(p<0.05)$ to compare male: female ratios for each clutch size. The leg measurements of $M$. raptorellus that emerged from $D$. suzukii pupae were non-parametric and analyzed using a Kruskal-Wallis test, followed by a post-hoc Dunn's test $(p<0.05)$. However, the leg measurements of individuals that emerged from $P$. vindemmiae were normally distributed and analyzed using a Student's $t$-test $(p<0.05)$.

\section{Results}

\subsection{Parasitoid and Predator Experiment with Multiple D. suzukii Life Stages}

At the end of the 15-day experiment, $M$. raptorellus and $P$. vindemmiae significantly reduced D. suzukii numbers by $40 \%$ and $43 \%$, respectively compared to the control $\left(\mathrm{F}_{3,27}=15.97, p<0.0001\right)$ (Figure 1). Only P. vindemmiae caused a decrease in the mean number of D. suzukii live adults $\left(\chi^{2}=25.54\right.$, $\mathrm{df}=3, p<0.0001)$. Both pupal parasitoids decreased the number of D. suzukii pupae $\left(\mathrm{F}_{3,27}=8.81\right.$, $p=0.0003$ ). Larval parasitoid $D$. isaea did not have an impact on any of the D. suzukii life stages. At the end of the experiment, there were $7.0 \pm 4.2$ live M. raptorellus and $14.3 \pm 2.7$ live P. vindemmiae (mean $\pm \mathrm{SD}$ ), but all individuals of $D$. isaea were dead.

After 15 days, there was a significant effect of predator species on the total number of all D. suzukii life stages recovered $\left(\mathrm{F}_{4,33}=14.01, p<0.0001\right)$. Orius insidiosus adults and C. carnea larvae reduced D. suzukii numbers by $49 \%$ and $32 \%$, respectively, whereas D. hesperus and P. maculiventris did not significantly reduce $D$. suzukii cumulative life stages compared to the control (Figure 2). Predators $O$. insidiosus and C. carnea caused a decrease in the number of $D$. suzukii live adults $\left(\chi^{2}=20.55, \mathrm{df}=4\right.$, $p=0.0004)$ and pupae $\left(\mathrm{F}_{4,33}=6.32, p=0.0007\right)$. Predators O. insidiosus and D. hesperus decreased the number of $D$. suzukii larvae $\left(\mathrm{F}_{4,33}=6.91, p=0.0004\right)$. Predator P. maculiventris did not have an impact on any of the $D$. suzukii life stages. At the end of the experiment, $4.5 \pm 3.50$. insidiosus, $2.4 \pm 1.5$ C. carnea, $13.0 \pm 0.9$ D. hesperus and $7.6 \pm 1.7$ P. maculiventris (mean $\pm \mathrm{SD}$ ) were recovered alive. 




Figure 1. Means ( $\pm \mathrm{SE}$ ) of D. suzukii cumulative life stages (larvae, pupae, and dead and alive adults) recovered after 15 days when exposed to female parasitoid wasps. Each arena ( $n=8$ per parasitoid wasp species) contained five D. suzukii mated females and raspberries at the beginning of the experiment, with 18 larval parasitoids added on day 4 and 18 pupal parasitoids added on day 9. Cumulative means with the same letter were not significantly different (Tukey's HSD, $p<0.05$ ).

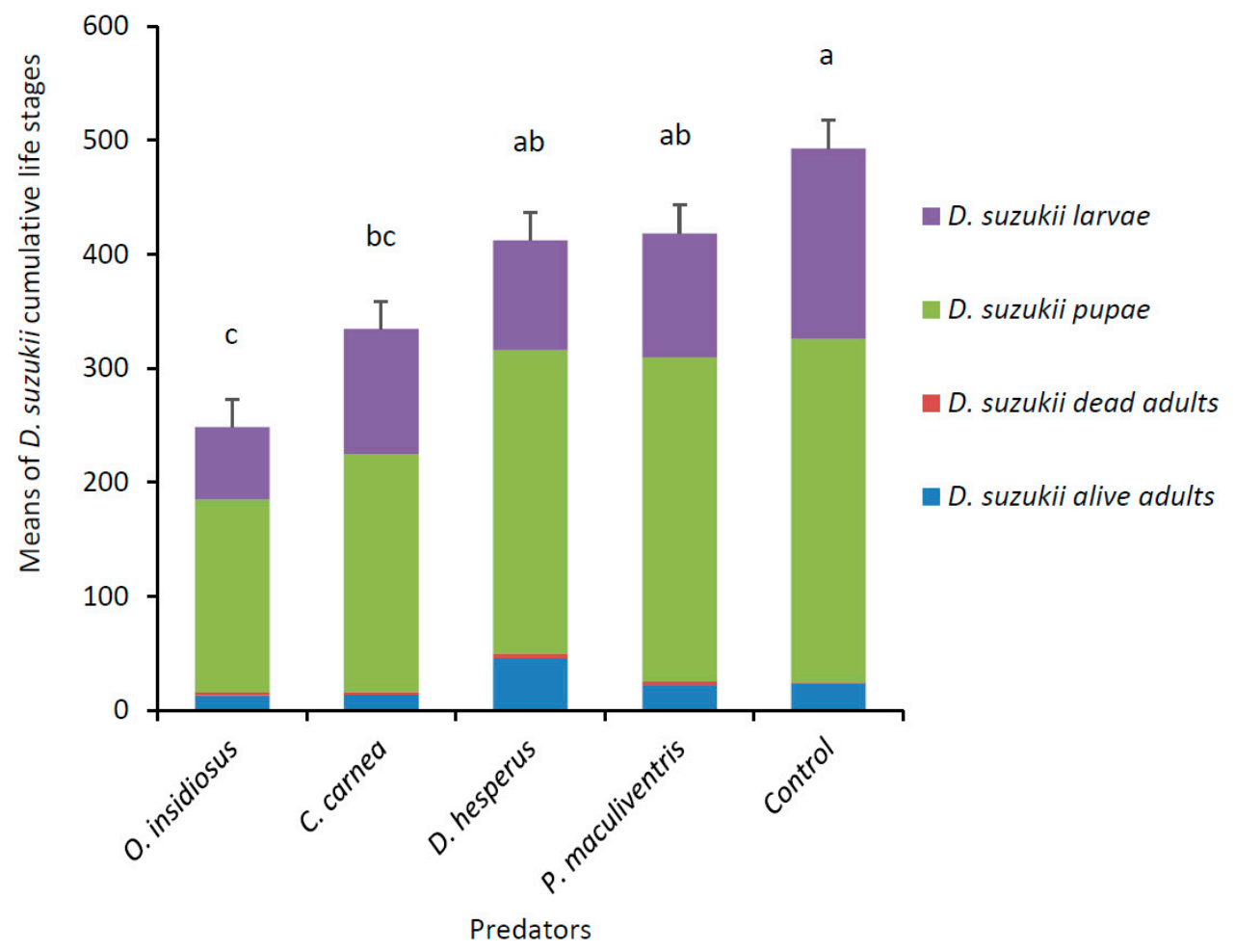

Figure 2. Means ( \pm SE) of $D$. suzukii cumulative life stages (larvae, pupae, and dead and alive adults) recovered after 15 days when exposed to predators. Each arena ( $n=8$ per predator species) contained five D. suzukii mated females and raspberries at the beginning of the experiment, with 18 predators added on day 3. Cumulative means with the same letter were not significantly different (Tukey's HSD, $p<0.05$ ). 


\subsection{Predator Experiment with Single D. suzukii Life Stage}

Predation occurred primarily on D. suzukii eggs and larvae (Figure 3). Predators C. carnea, D. hesperus and O. insidiosus were able to feed on D. suzukii eggs $\left(\chi^{2}=47.88, \mathrm{df}=4, p<0.0001\right)$ and predators C. carnea, O. insidiosus and P. maculiventris were able to feed on D. suzukii larvae $\left(\chi^{2}=34.54\right.$, $\mathrm{df}=4, p<0.0001)$. None of the four predators were able to predate significantly $D$. suzukii adults and pupae $\left(\chi^{2}=10.25, \mathrm{df}=4, p=0.0363 ; \chi^{2}=8.54, \mathrm{df}=4, p=0.0737\right)$. At the end of the experiment, all predators were found alive except for two D. hesperus. Most of the different life stages were recovered alive in the control treatments except for adults, nearly $50 \%$ of which died in the absence of food.

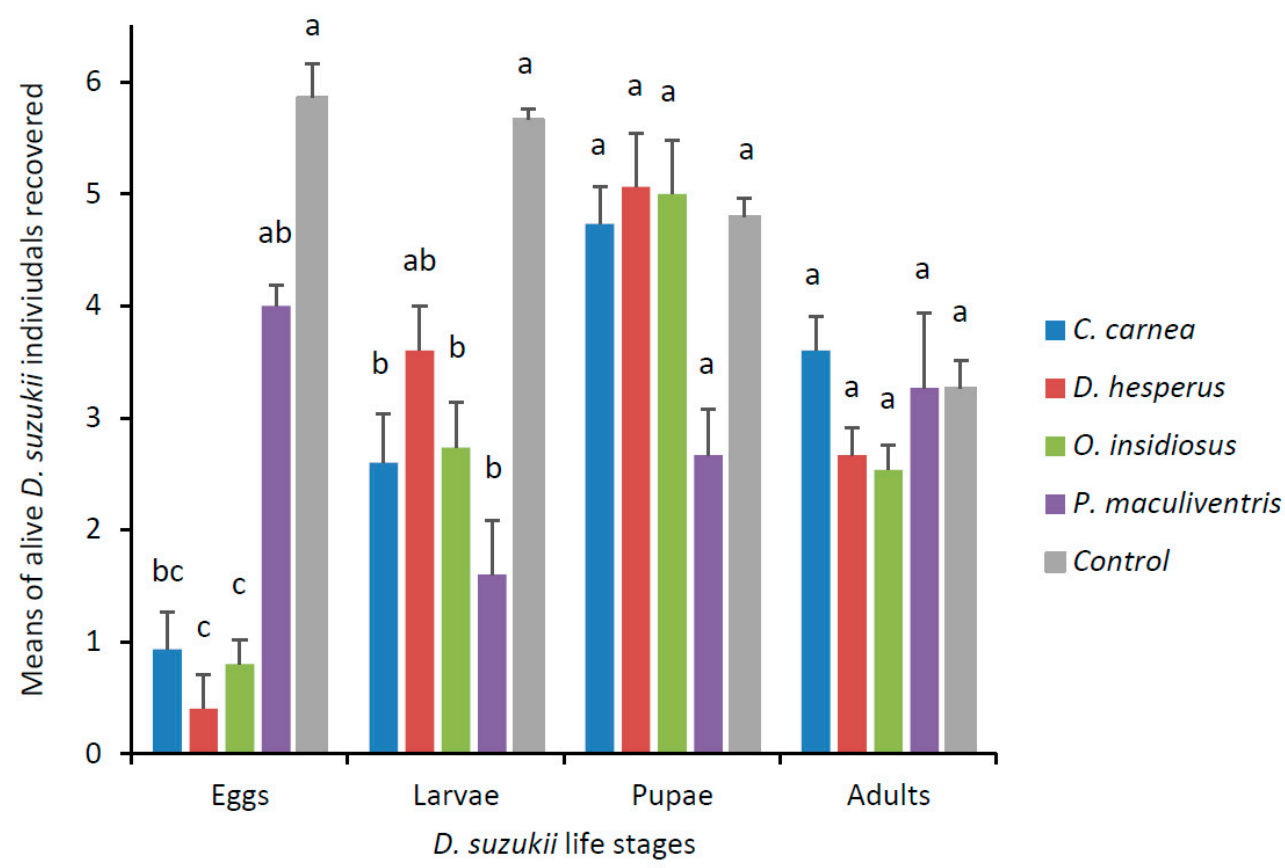

Figure 3. Mean ( \pm SEM) number of $D$. suzukii life stages recovered after 24-h exposure to predators (either larval C. carnea, adult $D$. hesperus, adult $O$. insidiosus or nymph $P$. maculiventris). Each arena ( $n=15$ per predator species) contained six D. suzukii (either eggs, larvae, pupae or adults) and one predator. Means for each life stages with the same letter were not significantly different (Kruskal-Wallis post-hoc Dunn's test, $p<0.05)$.

\subsection{Pupal Parasitoid Observations}

Muscidifurax raptorellus and P. vindemmiae both successfully parasitized $D$. suzukii pupae and had similar parasitism rates $\left(\mathrm{t}_{14}=0.28, p=0.7804\right)$ (Table 1$)$. There was a total of 810 parasitized D. suzukii pupae by $M$. raptorellus after 15 days out of 1866 in total, which produced an average of 1.9 parasitoid offspring (861 males and 674 females) from D. suzukii with an average of $43.9 \%$ females (Figure $4 \mathrm{a}$ ). For P. vindemmiae, there was a total of 839 parasitized D. suzukii pupae after 15 days out of 1873 in total, which produced an average of one parasitoid offspring (392 males and 447 females) from $D$. suzukii with an average of $53.5 \%$ females (Figure $4 \mathrm{a}$ ). For $M$. raptorellus, the percentage of female progeny decreased when the clutch size increased and the sex ratio of the clutch size containing three $(41.5 \%$ female), four (34.1\% female) and five (26.7\% female) parasitoids was significantly different than 1:1 $\left(\chi^{2}=12.42, \mathrm{df}=1, p=0.0004 ; \chi^{2}=13.36, \mathrm{df}=1, p=0.0003 ; \chi^{2}=6.53, \mathrm{df}=1, p=0.0106\right.$, respectively) (Figure 4a). As for P. vindemmiae, the sex ratio was not significantly different from $1: 1\left(\chi^{2}=3.61, \mathrm{df}=1\right.$, $p=0.0576$ ) (Figure 4a). There was one pupa from which six M. raptorellus adults (three males and three females) emerged that is not shown in the figure. The size of $M$. raptorellus from $M$. domestica pupae (control) is larger than from $D$. suzukii pupae but significantly different only for clutch sizes 3,4 and 5, for both males and females $\left(\chi^{2}=68.96, \mathrm{df}=5, p<0.0001 ; \chi^{2}=67.23, \mathrm{df}=5, p<0.0001\right.$, 
respectively) (Figure $4 \mathrm{~b}$ ). The size of $P$. vindemmiae from $D$. suzukii pupae in the experiment is not significantly different from the control, for both males and females $\left(t_{28}=0.00, p=0.9971 ; t_{28}=1.36\right.$, $p=0.1848$, respectively) (Figure $4 \mathrm{~b}$ ).

Table 1. Successful parasitism for each pupal parasitoid wasp species $(n=18)$ when exposed to D. suzukii developing in raspberries in the laboratory. Mean numbers of parasitized pupae with the same letter were not significantly different (Student's $t$-test, $p<0.05$ ).

\begin{tabular}{lccc}
\hline $\begin{array}{c}\text { Parasitoid } \\
\text { Species }\end{array}$ & $\begin{array}{c}\text { Mean Number of } \\
\text { D. suzukii Pupae per } \\
\text { Repetition ( } \pm \text { SD) }\end{array}$ & $\begin{array}{c}\text { Mean Number of Parasitized } \\
\text { D. suzukii Pupae per Repetition with } \\
\text { Parasitoid Emergence ( } \pm \text { SD) }\end{array}$ & $\begin{array}{c}\text { Successful } \\
\text { Parasitism (\%) }\end{array}$ \\
\hline $\begin{array}{l}\text { M. raptorellus } \\
\text { P. vindemmiae }\end{array}$ & $232.3 \pm 50.9$ & $100.9 \pm 26.1 \mathrm{a}$ & 43.4 \\
\hline
\end{tabular}
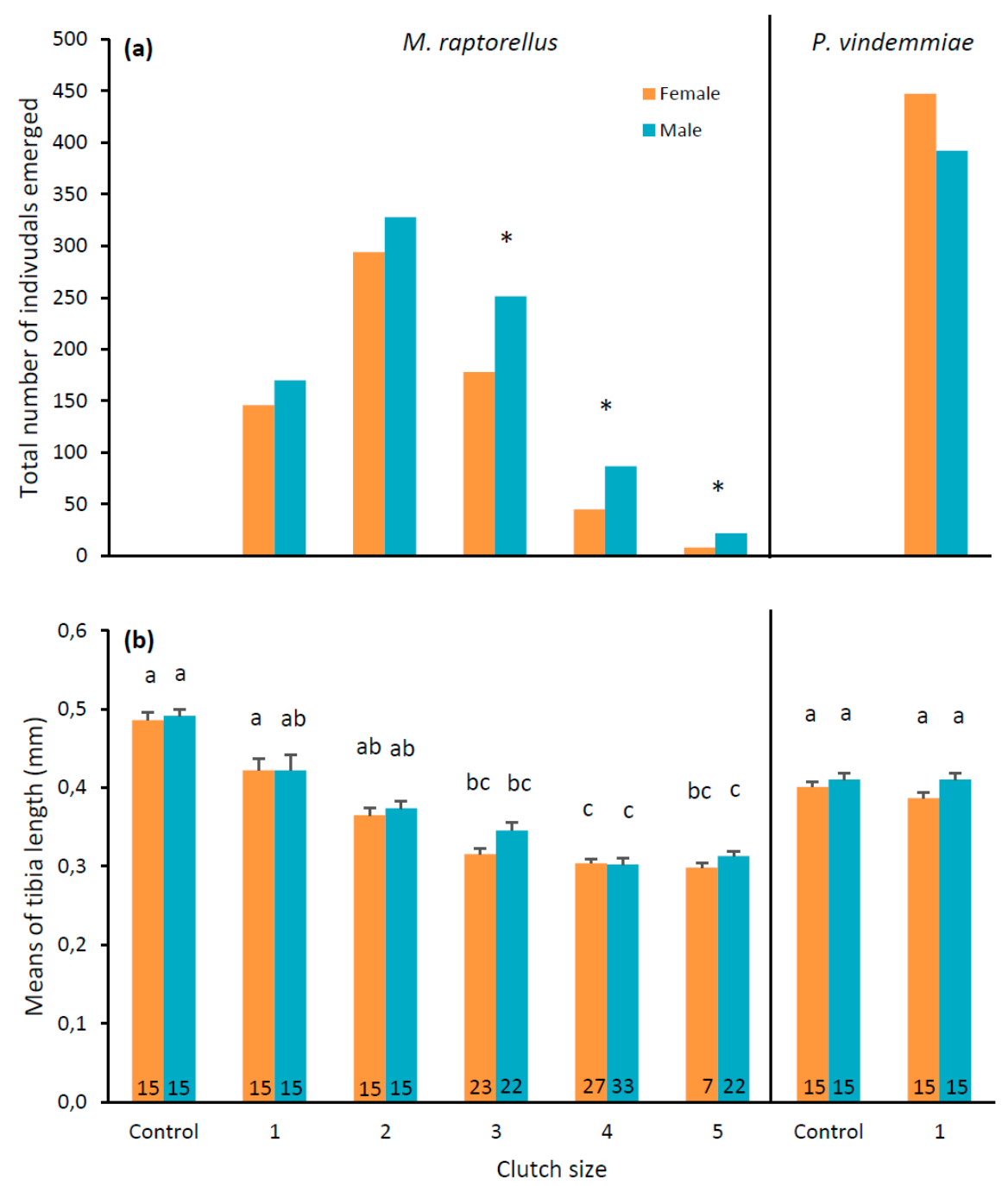

Figure 4. Total number of individuals (a) and means ( \pm SE) of left hind tibia length (b) of $M$. raptorellus and $P$. vindemmiae parasitoids that emerged from $D$. suzukii pupae at various clutch sizes in raspberries under laboratory conditions. Controls were M. raptorellus that emerged from $M$. domestica pupae and P. vindemmiae that emerged from D. suzukii pupae used in the rearing colony. Asterisks above bars in panel (a) indicate male: female ratios different than 1:1 for each clutch size (Chi-square, $p<0.05$ ), and bars with the same letter in panel (b) are not significantly different (M. raptorellus: Kruskal-Wallis post-hoc Dunn's test $p<0.05$; $P$. vindemmiae: Student's $t$-test, $p<0.05)$ for each sex and parasitoid species. Numbers in bars in panel (b) are the individuals measured. 


\section{Discussion}

Our results provided the first evidence of M. raptorellus's ability to parasitize D. suzukii pupae in the laboratory and demonstrated a level of efficacy comparable to $P$. vindemmiae. As with $P$. vindemmiae, M. raptorellus females were able to lay viable eggs in D. suzukii pupae and larvae readily fed on D. suzukii pupae, resulting in successful adult emergence. Both pupal parasitoid species also showed the same success rates of parasitism, although P. vindemmiae's rate in our study (45\%) is lower than that reported in Europe (57\% and 53\%) [20,39].

Diglyphus isaea was not able to parasitize D. suzukii, as no parasitoids emerged from D. suzukii larvae kept in growth chambers and most D. suzukii pupated successfully. We also observed no parasitoid adults alive in experimental arenas at the end of the experiment. Cheah and Coaker [40] reported that $D$. isaea females ignored live host larvae of Chromatomyia syngenesiae isolated from their mines, suggesting that the host-finding process required host plant stimuli. Diglyphus isaea is primarily a parasitoid of leafmining insects [30] and probably would simply not recognize and assess D. suzukii larvae at the surface of fruits as potential hosts [41].

Up to six gregarious $M$. raptorellus adults survived and emerged from a single D. suzukii pupa in this experiment, while Harvey et al. [42] reported up to 15 adults emerging from a single M. domestica pupa. However, the clutch size frequency decreased as the number of individuals emerging per host increased for both host species [42]. The most common clutch sizes in D. suzukii were 1-3 eggs, which was the same as in M. domestica [42]. Similarly, Petersen and Currey [29] noted that M. raptorellus laid 2-3 eggs per host when there was a high availability of $M$. domestica. Geden and Moon [43] reported that $M$. raptorellus produced 2.2-2.9 progeny per parasitized host from five dipteran hosts of different sizes, comparable to the production of an average of 1.9 parasitoids per D. suzukii pupae in this study. It appears that $M$. raptorellus does not strongly discriminate hosts for quality and does not adjust the clutch size according to the host size, knowing that D. suzukii pupae are more than ten times smaller than M. domestica pupae (Figure 5).

(a)

(b)

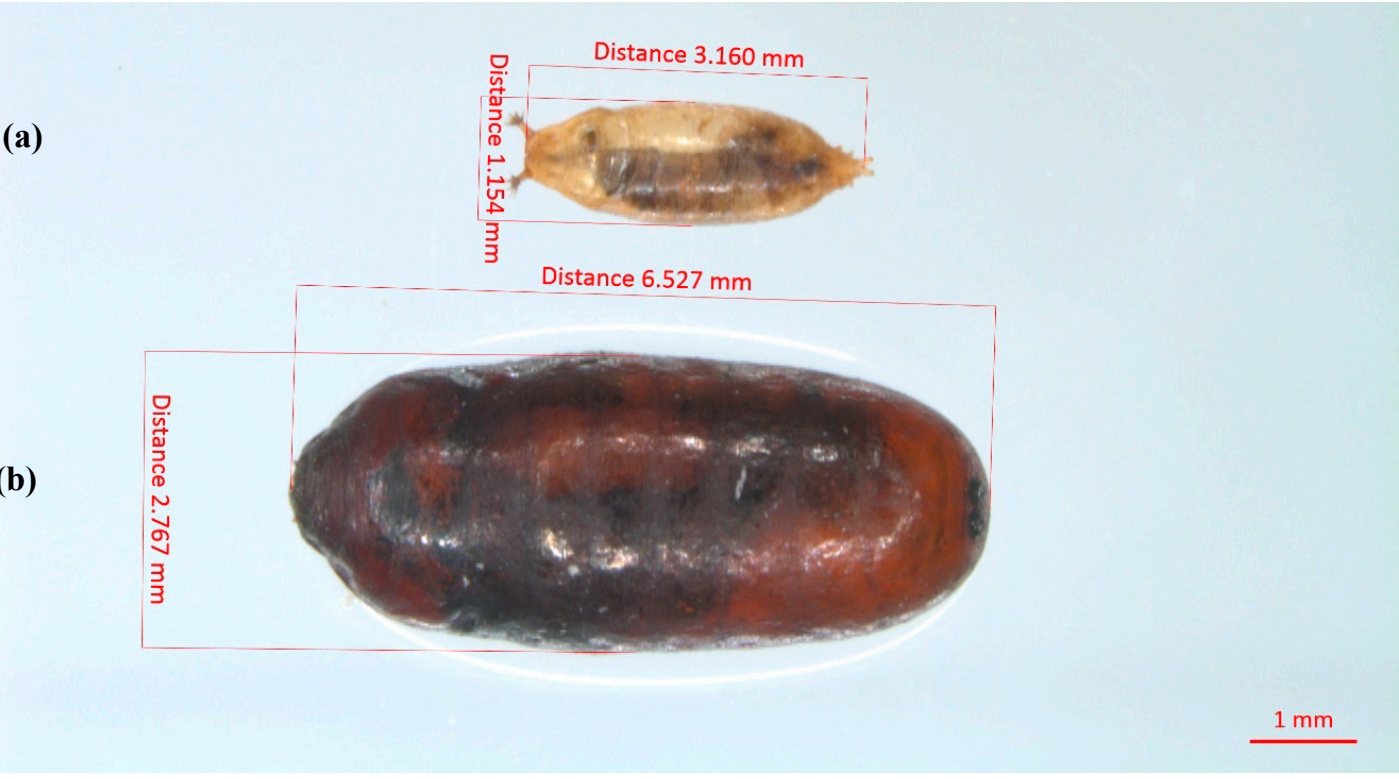

Figure 5. Size differences between host D. suzukii and M. domestica pupae. (a) parasitized D. suzukii pupa; (b) parasitized M. domestica pupa.

The clutch size influenced the parasitoid progeny size, as reported in Harvey et al. [42], and an $M$. raptorellus clutch size of three or more eggs, adult female and male wasp size decreased with D. suzukii as the host. Smaller female wasps may result in reduced fitness, as the ability to control dispersal and lifetime egg production and reproductive success may be reduced [38]. However, as 
there was no significant difference between the sizes of $M$. raptorellus that emerged from $M$. domestica (control) and from D. suzukii (1-2 eggs per host), D. suzukii, as the host, may not cause reduced fitness for most of the $M$. raptorellus progeny.

However, regardless of the clutch size (1-5), we observed high variability in the size of $M$. raptorellus siblings of both sexes within the same pupae. Furthermore, most pupae with a single emergent parasitoid also contained small dead larvae of non-emerged parasitoids, which would explain the different sizes of singly emerged adults. Size variability, irrespective of the clutch size, is typical in gregarious idiobiont parasitoids, as many offspring can develop inside a single host [44]. For idiobiont species such as $M$. raptorellus that paralyze their host, host development is stopped at oviposition and the resources are then immutable, as the amount of food available inside the pupae does not increase $[28,38]$. Therefore, space and resources are limited, and competition increases as more parasitoid larvae feed on the host.

The low female ratio of $M$. raptorellus from $D$. suzukii hosts may be explained by the general sex-allocation theory that parasitoid wasps will invest in female offspring in larger hosts and use male eggs for less-than-optimal hosts [41,45]. Harvey and Gols [46] reported that M. raptorellus had 60\% female progeny in $M$. domestica host and $76 \%$ female progeny in a larger host, Calliphora vomitoria Linnaeus, and as the clutch size increased, the percentage of female progeny increased in the latter host from $52 \%$ with a clutch size of one and two eggs to $81 \%$ with a clutch size of five eggs or more. We observed the opposite trend in this experiment with the smaller D. suzukii host-as the clutch size increased, the percentage of female progeny decreased from $44 \%$ to $27 \%$. However, as there was no significant difference from a 1:1 sex ratio of $M$. raptorellus progeny from $D$. suzukii when the clutch size was 1-2 eggs, D. suzukii pupa may be a suitable host for most of the $M$. raptorellus progeny.

As expected, the solitary parasitoid P. vindemmiae produced one parasitoid per D. suzukii pupa in the control and experiment. The sex ratio of progeny was not different from 1:1, and the percentage of female progeny (53\%) was similar to the parent colony at AAFC Agassiz [47].

Idiobiont ectoparasitoids such as $M$. raptorellus and $P$. vindemmiae are often associated with concealed hosts [14]. Therefore, D. suzukii pupae hidden among decomposed raspberries inside the experimental arenas may represent a suitable host for these parasitoids. Both ectoparasitoid species tend to be more adaptable in their biological response to different hosts and are likely to search for a specific type of habitat or host location instead of a specific type of host itself [14]. This suggests that $M$. raptorellus may be a good pupal parasitoid of $D$. suzukii pupae fallen from fruits and buried in the soil.

The results from our predator experiments with single and multiple $D$. suzukii life stages showed that $O$. insidiosus and $C$. carnea were efficient $D$. suzukii predators. By conducting a, no-choice experiment in a simple environment, we determined which easily accessible D. suzukii life stages were attacked by selected predators. We found that P. maculiventris fed only on larvae, and D. hesperus fed only on eggs, while C. carnea and O. insidiosus both fed on D. suzukii eggs and larvae. None of the predators appeared to be able to attack pupal or adult D. suzukii, but we observed opportunistic feeding by some predators on adults that were weak or dead.

Prey finding and acceptance can be affected by predator hunting and mobility capacities, nutritional benefits and the chemical composition of the prey cuticle [41]. Though destroyed D. suzukii pupal cases were found in experimental arenas, pupal cuticles may be impenetrable by predatory bugs and lacewings with piercing-sucking mouthparts. Nearly all predators mentioned in studies that report predation of D. suzukii pupae have chewing mouthparts [23,48,49]. Adult flies may be difficult for predators to capture in small experimental arenas where flying insects are too confined. Cuthbertson et al. [22] reported significant predation on adult flies by Orius spp. in a small experimental arena but only after $72 \mathrm{~h}$. We also observed that D. suzukii eggs may be too small for P. maculiventris which possess a large proboscis to stab and carry their prey.

By conducting a more complex experiment with all D. suzukii life stages simultaneously present in raspberries, we determined predator efficiency that mimics field situations. Podisus maculiventris 
and $D$. hesperus reduced D. suzukii numbers by $15 \%$ and $16 \%$ respectively, but suppression was not significantly different from the control. It is likely that these two predators were not able to prevent exponential D. suzukii population growth because they only prey on one life stage, as shown in the no-choice trial. In contrast, C. carnea and O. insidiosus reduced D. suzukii numbers by $32 \%$ and $49 \%$, respectively. The efficacy of $C$. carnea and $O$. insidiosus in a more complex environment may be explained by their ability to prey on two D. suzukii life stages, as shown in the no-choice trial. Therefore, it appears that predators that feed primarily on early D. suzukii life stages, such as eggs and larvae, can suppress D. suzukii population increases inside the experimental arena over the course of the experiment, while those that are only capable of consuming one life stage are less effective. The presence of raspberries in the experimental arenas may also have played a role in the efficacy of the predators and their foraging behavior. We observed O. insidiosus and C. carnea foraging on the surface of fruits for D. suzukii eggs and larvae, as was reported for O. insidiosus in Woltz et al. [25]. As the raspberries started to decompose, all the predators gained easier access to D. suzukii life stages. In addition, the suppression of D. suzukii may also be attributable to nonconsumptive predator effects [50]. Predators may have physically disturbed D. suzukii females during oviposition which would have resulted in reduced D. suzukii numbers.

\section{Conclusions}

Our study provided new additional information on the host range of the pupal parasitoid M. raptorellus and its ability to parasitize invasive D. suzukii. Muscidifurax raptorellus had similar parasitism rates to $P$. vindemmiae, and both reduced $D$. suzukii numbers in raspberries in the laboratory by 40 and $43 \%$, respectively. Studies have shown that $P$. vindemmiae parasitized $D$. suzukii in the laboratory and field. However, in a natural environment, $P$. vindemmiae was not sufficiently abundant to prevent exponential D. suzukii population growth $[39,51,52]$. As a potential solution, $M$. raptorellus is commercially available in Canada and the United States and could be released in sufficient numbers to suppress D. suzukii. Further study on the growth and development of M. raptorellus in D. suzukii pupae is needed to better understand the host-parasitoid interactions.

Our results also confirmed that predatory natural enemies, O. insidiosus and C. carnea, were effective at reducing D. suzukii by almost $50 \%$. In conclusion, all four of the effective natural enemies are present in agroecosystems in North America, were complementary in the life stages of D. suzukii they attacked and may play a role in the suppression of D. suzukii in fruit crop fields. Further research is needed to precisely measure the combined impacts of multiple natural enemies under field conditions, to evaluate a possible preference for alternative preys or hosts, and to optimize and support the augmentative releases of commercially-available species.

Author Contributions: Conceptualization, all authors; Funding acquisition, and project administration, A.F.; Supervision, A.F., V.F., and J.R.; Methodology, P.B. and A.F.; Investigation, formal analysis, visualization, and writing-original draft, P.B.; Writing—review and editing, J.R., V.F., and A.F.

Funding: This research was funded by Programme Innov'Action Agroalimentaire, a program under the Cultivons l'Avenir Volet 2 agreement between the Ministère de l'Agriculture, des Pêcheries et de l'Alimentation du Québec and Agriculture and Agri-Food Canada. We also thank the Centre SĖVE for their financial support.

Acknowledgments: The authors would like to thank Véronique Roy-Blais, Alessandro Dieni, Élisabeth Ménard, Sarah Jollois, Marie-Pier Ricard, Kim Ostiguy and all the students and colleagues at IRDA who helped during the project. We are grateful to all the researchers who shared constructive comments in the early stages of protocols: Daniel Cormier, Conrad Cloutier, Véronique Martel, Martine Dorais and Raymond-Marie Duchesne. We are thankful to Michèle Grenier for her assistance with statistical analysis. We also thank Paul Abram for P. vindemmiae samples.

Conflicts of Interest: The authors declare no conflict of interest. 


\section{References}

1. Bolda, M.P.; Goodhue, R.E.; Zalom, F.G. Spotted wing drosophila: Potential economic impact of a newly established pest. Agric. Res. Econ. Update 2010, 13, 5-8.

2. Lee, J.C.; Bruck, D.J.; Dreves, A.J.; Ioriatti, C.; Vogt, H.; Baufield, P. In Focus: Spotted wing drosophila, Drosophila suzukii, across perspectives. Pest Manag. Sci. 2011, 67, 1349-1351. [CrossRef] [PubMed]

3. Lee, J.C.; Bruck, D.J.; Curry, H.; Edwards, D.; Haviland, D.R.; van Steenwyk, R.A. The susceptibility of small fruits and cherries to the spotted-wing drosophila, Drosophila suzukii. Pest Manag. Sci. 2011, 67, 1358-1367. [CrossRef] [PubMed]

4. Walsh, D.B.; Bolda, M.P.; Goodhue, R.E.; Dreves, A.J.; Lee, J.; Bruck, D.J.; Walton, V.M.; O’Neal, S.D.; Zalom, F.G. Drosophila suzukii (Diptera: Drosophilidae): Invasive pest of ripening soft fruit expanding its geographic range and damage potential. J. Integr. Pest Manag. 2011, 2, G1-G7. [CrossRef]

5. Farnsworth, D.; Hamby, K.A.; Bolda, M.; Goodhue, R.E.; Williams, J.C.; Zalom, F.G. Economic analysis of revenue losses and control costs associated with the spotted wing drosophila, Drosophila suzukii (Matsumura), in the California raspberry industry. Pest Manag. Sci. 2017, 73, 1083-1090. [CrossRef] [PubMed]

6. Beers, E.H.; van Steenwyk, R.A.; Shearer, P.W.; Coates, W.W.; Grant, J.A. Developing Drosophila suzukii management programs for sweet cherry in the western United States. Pest Manag. Sci. 2011, 67, 1386-1395. [CrossRef] [PubMed]

7. Emiljanowicz, L.M.; Ryan, G.D.; Langille, A.; Newman, J. Development, reproductive output and population growth of the fruit fly pest Drosophila suzukii (Diptera: Drosophilidae) on artificial diet. J. Econ. Entomol. 2014, 107, 1392-1398. [CrossRef] [PubMed]

8. SAgE Pesticides. Available online: https://www.sagepesticides.qc.ca/ (accessed on 15 November 2018).

9. Cormier, D.; Veilleux, J.; Firlej, A. Exclusion net to control spotted wing drosophila in blueberry fields. IOBC WPRS Bull. 2015, 109, 181-184.

10. Baroffio, C.; Kuonen, F.; Huber, B.; Kopp, M.C.; Marazzi, C.; Thoss, H.; Vulliemin, D.; Zurfluh, M. Drosophila suzukii: Stratégie 2018 pour les petits fruits. Plantes Agroscope Fiche Tech. 2018, 78, 1-2.

11. Haye, T.; Girod, P.; Cuthbertson, A.G.; Wang, X.G.; Daane, K.M.; Hoelmer, K.A.; Baroffio, C.; Zhang, J.P.; Desneux, N. Current SWD IPM tactics and their practical implementation in fruit crops across different regions around the world. J. Pest Sci. 2016, 89, 643-651. [CrossRef]

12. Klick, J.; Yang, W.Q.; Walton, V.M.; Dalton, D.T.; Hagler, J.R.; Dreves, A.J.; Lee, J.C.; Bruck, D.J. Distribution and activity of Drosophila suzukii in cultivated raspberry and surrounding vegetation. J. Appl. Entomol. 2015, 140, 37-46. [CrossRef]

13. Knoll, V.; Ellenbroek, T.; Romeis, J.; Collatz, J. Seasonal and regional presence of hymenopteran parasitoids of Drosophila in Switzerland and their ability to parasitize the invasive Drosophila suzukii. Sci. Rep. 2017, 7, 40697. [CrossRef] [PubMed]

14. Hajek, A.E.; Eilenberg, J. Natural Enemies: An Introduction to Biological Control, 2nd ed.; Cambridge University Press: Cambridge, UK, 2018; 452p.

15. Cloutier, C.; Cloutier, C. Les solutions biologiques de lutte pour la répression des insectes et acariens ravageurs des cultures. In La Lutte Biologique; Vincent, C., Coderre, D., Editeur, G., Eds.; Morin: Boucherville, QC, Canada, 1992; Chapitre 2; 672p.

16. Rossi Stacconi, M.V.; Grassi, A.; Ioriatti, C.; Anfora, G. Augmentative releases of Trichopria drosophilae for the suppression of early season Drosophila suzukii populations. BioControl 2018, 64, 9-19. [CrossRef]

17. Daane, K.M.; Wang, X.G.; Biondi, A.; Miller, B.; Miller, J.C.; Riedl, H.; Shearer, P.W.; Guerrieri, E.; Giorgini, M.; Buffington, M.; et al. First exploration of parasitoids of Drosophila suzukii. J. Pest Sci. 2016, 89, 823-835. [CrossRef]

18. Hajek, A.E.; Hurley, B.P.; Kenis, M.; Garnas, J.R.; Bush, S.J.; Wingfield, M.J.; van Lenteren, J.C.; Cock, M.J.W. Exotic biological control agents: A solution or contribution to arthropod invasions? Biol. Invasions 2016, 18, 953-969. [CrossRef]

19. Wang, X.G.; Kaçar, G.; Biondi, A.; Daane, K.M. Foraging efficiency and outcomes of interactions of two pupal parasitoids attacking the invasive spotted wing drosophila. Biol. Control 2016, 96, 64-71. [CrossRef]

20. Chabert, S.; Allemand, R.; Poyet, M.; Eslin, P.; Gibert, P. Ability of European parasitoids (Hymenoptera) to control a new invasive Asiatic pest, Drosophila suzukii. Biol. Control 2012, 63, 40-47. [CrossRef] 
21. Thistlewood, H.M.; Gibson, G.A.; Gillespie, D.R.; Fitzpatrick, S.M. Drosophila suzukii (Matsumura), Spotted Wing Drosophila (Diptera: Drosophilidae). In Biological Control Programmes in Canada 2001-2012; Mason, P.G., Gillespie, D.R., Eds.; CAB International: Wallingford, UK, 2013; Chapter 21; pp. 152-155.

22. Cuthbertson, A.G.S.; Blackburn, L.F.; Audsley, N. Efficacy of commercially available invertebrate predators against Drosophila suzukii. Insects 2014, 5, 952-960. [CrossRef] [PubMed]

23. Gabarra, R.; Riudavets, J.; Rodriguez, G.A.; Pujade-Villar, J.; Arnó, J. Prospects for the biological control of Drosophila suzukii. BioControl 2015, 60, 331-339. [CrossRef]

24. Renkema, J.M.; Telfer, Z.; Gariepy, T.; Hallett, R.H. Dalotia coriaria as a predator of Drosophila suzukii: Functional responses, reduced fruit infestation and molecular diagnostics. Biol. Control 2015, 89, 1-10. [CrossRef]

25. Woltz, J.M.; Donahue, K.M.; Bruck, D.J.; Lee, J.C. Efficacy of commercially available predators, nematodes and fungal entomopathogens for augmentative control of Drosophila suzukii. J. Appl. Entomol. 2015, 139, 759-770. [CrossRef]

26. Firlej, A.; Vanoosthuyse, F. La Drosophile à Ailes Tachetées, un Ravageur des Petits Fruits au Québec; Synthèse Bibliographique; Institut de Recherche et de Développement en Agroenvironnement (IRDA) et Partenaires: Saint-Bruno-de-Montarville, QC, Canada, 2017; 93p.

27. Schetelig, M.F.; Lee, K.Z.; Otto, S.; Talmann, L.; Stökl, J.; Degenkolb, T.; Vilcinskas, A.; Halitschke, R. Environmentally sustainable pest control options for Drosophila suzukii. J. Appl. Entomol. 2017, 142, 3-17. [CrossRef]

28. Legner, E.F. Inheritance of gregarious and solitary oviposition in Muscidifurax raptorellus Kogan and Legner (Hymenoptera: Pteromalidae). Can. Entomol. 1987, 119, 791-808. [CrossRef]

29. Petersen, J.J.; Currey, D.M. Timing of releases of gregarious Muscidifurax raptorellus (Hymenoptera: Pteromalidae) to control flies associated with confined beef cattle. J. Agric. Entomol. 1996, 13, 55-63.

30. Minkenberg, O.P.; Van Lenteren, J.C. The Leafminers, Liriomyza bryoniae and L. trifolii (Diptera: Agromyzidae), Their Parasites and Host Plants: A Review; Agricultural University: Wageningen, The Netherlands, 1986; pp. 16-17.

31. Featured Creatures. Available online: http://entnemdept.ufl.edu/creatures/beneficial/podisus_ maculiventris.htm (accessed on 15 November 2018).

32. McGregor, R.R.; Gillespie, D.R.; Quiring, D.M.; Foisy, M.R. Potential use of Dicyphus hesperus Knight (Heteroptera: Miridae) for biological control of pests of greenhouse tomatoes. Biol. Control 1999, 16, 104-110. [CrossRef]

33. Arnó, J.; Riudavets, J.; Gabarra, R. Survey of host plants and natural enemies of Drosophila suzukii in an area of strawberry production in Catalonia (northeast Spain). IOBC Bull. 2012, 80, 29-34.

34. Albouy, V. La Lutte Biologique au Jardin; Éditions Quae: Paris, France, 2012; 102p.

35. New, T.R. The biology of Chrysopidae and Hemerobiidae (Neuroptera), with reference to their usage as biocontrol agents: A review. Trans. R. Entomol. Soc. Lond. 1975, 127, 115-140. [CrossRef]

36. Renkema, J.M.; Cuthbertson, A.G.S. Impact of multiple natural enemies on immature Drosophila suzukii in strawberries and blueberries. BioControl 2018, 63, 719-728. [CrossRef]

37. Jervis, M.A. Insects as Natural Enemies: A Practical Perspective; Springer Science \& Business Media: Dordrecht, The Netherlands, 2007; 748p.

38. Godfray, H.C.J. Parasitoids: Behavioral and Evolutionary Ecology; Princeton University Press Books: Princeton, NJ, USA, 1994; 473p.

39. Rossi Stacconi, M.V.; Grassi, A.; Dalton, D.T.; Miller, B.; Ouantar, M.; Loni, A.; Ioriatti, C.; Walton, V.M.; Anfora, G. First field records of Pachycrepoideus vindemmiae as a parasitoid of Drosophila suzukii in European and Oregon small fruit production areas. Entomolgia 2013, 1, 11-16.

40. Cheah, C.A.; Coaker, T.H. Host finding and discrimination in Diglyphus isaea, a parasitoid of the chrysanthemum leaf miner, Chromatomyia syngenesiae. Biocontrol Sci. Technol. 1992, 2, 109-118. [CrossRef]

41. Van Driesche, R.; Hoddle, M.; Center, T. Control of Pests and Weeds by Natural Enemies: An Introduction to Biological Control; Blackwell Publishing: Singapore, 2008; 473p.

42. Harvey, J.; Vet, L.; Jiang, N.; Gols, R. Nutritional ecology of the interaction between larvae of the gregarious ectoparasitoid, Muscidifurax raptorellus (Hymenoptera: Pteromalidae), and their pupal host, Musca domestica (Diptera: Muscidae). Physiol. Entomol. 1998, 23, 113-120. [CrossRef] 
43. Geden, C.J.; Moon, R.D. Host ranges of gregarious muscoid fly parasitoids: Muscidifurax raptorellus (Hymenoptera: Pteromalidae), Tachinaephagus zealandicus (Hymenoptera: Encyrtidae), and Trichopria nigra (Hymenoptera: Diapriidae). Environ. Entomol. 2009, 38, 700-707. [CrossRef] [PubMed]

44. Mackauer, M.; Sequeira, R. Patterns of Development in Insect Parasites. In Parasites and Pathogens of Insects; Beckage, N., Thompson, S., Federici, B., Eds.; Academic Press, Elsevier: Cambridge, MA, USA, 1993; 364p.

45. Charnov, E.L. The Theory of Sex Allocation; Princeton University Press Books: Princeton, NJ, USA, 1982; 355p.

46. Harvey, J.A.; Gols, G.J.Z. The influence of host quality on progeny and sex allocation in the pupal ectoparasitoid, Muscidifurax raptorellus (Hymenoptera: Pteromalidae). Bull. Entomol. Res. 1998, 88, 299-304. [CrossRef]

47. Abram, P.; Agriculture and Agri-Food Canada, Agassiz, BC, Canada. Personal communication, 2019.

48. Ballman, E.S.; Collins, J.A.; Drummond, F.A. Pupation Behavior and Predation on Drosophila suzukii (Diptera: Drosophilidae) Pupae in Maine Wild Blueberry Fields. J. Econ. Entomol. 2017, 110, 2308-2317. [CrossRef] [PubMed]

49. Woltz, J.M.; Lee, J.C. Pupation behavior and larval and pupal biocontrol of Drosophila suzukii in the field. Biol. Control 2017, 110, 62-69. [CrossRef]

50. Preisser, E.L.; Bolnick, D.I.; Benard, M.F. Scared to death? The effects of intimidation and consumption in predator-prey interactions. Ecology 2005, 86, 501-509. [CrossRef]

51. Rossi Stacconi, M.V.; Buffington, M.; Daane, K.M.; Dalton, D.T.; Grassi, A.; Kaçar, G.; Miller, B.; Miller, J.C.; Baser, N.; Ioriatti, C.; et al. Host stage preference, efficacy and fecundity of parasitoids attacking Drosophila suzukii in newly invaded areas. Biol. Control 2015, 84, 28-35. [CrossRef]

52. Miller, B.; Anfora, G.; Buffington, M.; Daane, K.M.; Dalton, D.T.; Hoelmer, K.M.; Rossi-Stacconi, M.V.; Grassi, A.; Ioriatti, C.; Loni, A.; et al. Seasonal occurrence of resident parasitoids associated with Drosophila suzukii in two small fruit production regions of Italy and the U.S.A. Bull. Insectol. 2015, 68, 255-263.

(C) 2019 by the authors. Licensee MDPI, Basel, Switzerland. This article is an open access article distributed under the terms and conditions of the Creative Commons Attribution (CC BY) license (http:/ / creativecommons.org/licenses/by/4.0/). 